\title{
The Feasibility of Applying Qiang Embroidery Pattern Art in Wenchuan to Cultural and Creative Products
}

\author{
Huili Han ${ }^{1}$ Deshu $\mathrm{Yu}^{2}$ Xuefeng Liu ${ }^{1, *}$ Tian Wen ${ }^{2}$
}

\author{
${ }^{1}$ Chengdu Agricultural College, Chengdu, Sichuan 611130, China \\ ${ }^{2}$ Weizhou Normal School, Wenchuan, Sichuan 623000, China \\ *Corresponding author. Email: 174172448@qq.com
}

\begin{abstract}
Qiang embroidery is an important part of Qiang culture, and its embroidery pattern is not only a manifestation of the daily life of Qiang people, but also an expression of the spiritual culture of Qiang people, which is integrated with the life of Qiang people. Taking the Wenchuan region as an example, this paper studies the Qiang embroidery pattern art and discusses the feasibility of applying Qiang embroidery pattern art to cultural and creative products based on field investigations, which will play a certain role in the spread, protection, inheritance and development of Qiang traditional culture, and enhance national self-confidence and promote national culture. In this way, it seeks a more suitable communication method and development direction for the traditional national crafts represented by Qiang embroidery.
\end{abstract}

Keywords: Qiang embroidery, pattern art, cultural and creative products

\section{INTRODUCTION}

Qiang embroidery is not only an excellent folk craft of Qiang nationality, but also the essence of Qiang culture. It is an important part of the folk art of the Chinese nation with strong Qiang customs and strong historical and cultural accumulation. There is no writing in Qiang nationality, and Qiang embroidery pattern has become an important carrier to record national life and folk feelings. Through the Qiang embroidery patterns, people can understand the history and culture of the Qiang nationality, understand its national psychological consciousness, thinking mode and cultural ideology, and trace its migration, character and aesthetic consciousness.

\section{THE ORIGIN OF QIANG EMBROIDERY PATTERNS}

Qiang people do not have their own national characters, and there are few historical records of Qiang embroidery, which are basically simple summaries or introductions. At present, there is no clear conclusion about the history of Qiang embroidery, which is still in the exploration. The history of Qiang embroidery can be traced back to the primitive society. The patterns on the ancient painted pottery unearthed in Yingpanshan site of Maoxian County (6000 years ago) are similar to those on the Qiang people's girdle. The swirl patterns

*Fund: This article is the staged achievements of the innovation platform of the Qiang embroidery and paper-cutting arts and crafts skills in Sichuan Province. on the bronze and pottery binaural pot unearthed in Maoxian County are similar to those on "Yunyun shoes". [1] However, against the background of commodity economy, the original national economy and culture have been impacted. Most of the young people flock to the city. They are unwilling to spend time and energy to inherit and carry forward the traditional culture of their own nation after feeling the prosperity of the city. The pursuit of economy by the young people has made the traditional culture lose the soil, and the development of Qiang embroidery is difficult.

Qiang embroidery pattern is a symbol with national characteristics that is refined / summarized / accumulated in the same way as the images heard and seen in nature and expresses the love for life and the reverence for nature in the production and life of Qiang women. There is no fixed style or fixed personnel engaged in pattern design. All of draft are made by themselves, and the shape is free and irregular. The culture of the Qiang nationality is displayed through the Qiang embroidery patterns. The Qiang embroidery patterns have strong local flavor and cultural heritage. [2] In the long years of evolution, they have become the most representative decorative patterns of the Qiang nationality. The unique national decoration and practicability are the crystallization of the wisdom of the Qiang people. 


\section{Characteristics OF QIANG EMBROIDERY PATTERNS IN WENCHUAN}

The development of Qiang embroidery depends on the oral teaching of Qiang women. Different patterns are designed with different needlework. Qiang embroidery patterns are colorful and various, implying wealth, auspiciousness and peace. Qiang embroidery patterns are primitive, regional, abstract and allegorical.

Wenchuan County, located next to the eastern edge of the Qinghai-Tibet Plateau and in the northwest of Sichuan Province, is the throat of Aba area. The profound traditional culture and rich material resources of Wenchuan County create distinctive Qiang embroidery, which is represented by Radish village and Qiangfeng village.

\section{A. Radish village}

Radish village, located next to the northwest edge of Sichuan Province, is the largest and oldest village of Huangni Qiang nationality in the world. It is a typical alpine village in Qiang area. The geographical location is relatively closed, and the productivity development is relatively slow. Therefore, the early Qiang embroidery materials are relatively limited, and they are mostly made of hemp rope and coarse cloth, mainly in black and white. [3] At present, the local traffic has been improved, and there are many kinds of embroidery threads, including cotton thread, cashmere, acrylic fiber, wool, silk thread, etc. The cloth is not limited to plain cotton and hemp, and the color bottom cloth is widely used, mainly red, blue and yellow. The patterns are mostly flowers, animals, plants and insects. The design of Qiang embroidery in Radish village is simple and clear, which reflects the original worship and religious belief of Qiang people. However, influenced by foreign culture, the traditional color and shape of Qiang embroidery have changed accordingly. From the perspective of development, it is inevitable that the material, style and shape of Qiang embroidery will change.

\section{B. Qiangfeng village}

Qiangfeng village, located on the edge of Minjiang River, is the oldest Qiang village and the first Qiang village encountered when entering the Qiang residential area from Chengdu, so it is called the first village of western Qiang nationality. In 1996, Qiangfeng village was awarded "the hometown of Chinese folk art" by the Ministry of Culture. Qiang embroidery doesn't draw patterns or draft. The embroidery is vivid and natural. The color is red and green, and the design is simple and unrestrained. [4] Most of the themes reflect the natural creatures in real life, such as flowers, fruits, animals and people.

\section{ANALYSIS ON THE FEASIBILITY OF APPLYING QIANG EMBROIDERY PATTERN ART TO CULTURAL AND CREATIVE PRODUCTS}

In the "Opinion on strengthening the protection of intangible cultural heritage" issued by the state in 2005 , the guideline of intangible cultural heritage protection is "protection first, rescue first, reasonable utilization, inheritance and development", among which "reasonable utilization, inheritance and development" is to integrate intangible cultural heritage into modern life, inherit and protect historical and cultural heritage. There is no contradiction between cultural and creative industry and intangible cultural heritage protection. It is to combine the national culture and cultural and creative products contained in the Qiang embroidery pattern art. With multi-dimensional and all-round redesign, taking cultural and creative as the root and the Qiang embroidery pattern art as the soul, the national characteristics and culture of the Qiang nationality can be propagandized and promoted. On the basis of protecting the uniqueness of Qiang embroidery pattern art, it promotes cultural development and produces certain economic value.

\section{A. Cultural and creative products}

In "Attributes and characteristics of cultural and creative products", Wei Pengju believes that cultural and creative products refer to products from the field of cultural and creative industries, whose content and external carriers are interdependent and inseparable. In other words, cultural and creative products take creativity as the core, and integrate the spiritual and immaterial ideas from traditional culture into the products through re-design to convey the connotation of national culture itself. Cultural and creative products will be derived from concrete objects, become the object of consumer consumption, and promote the culture. [5]

Cultural and creative products meet the spiritual needs of consumers in the dissemination of culture, integrating practicability and decoration. In an ideal state, designers design cultural and creative products for feelings, and consumers consume cultural and creative products for feelings. Excellent cultural and creative products not only meet the material and spiritual cultural needs of consumers, but also guide consumers to have cultural appreciation, spread and promote national excellent culture. Most of the cultural and creative products are consumed with the audiences' memory after the field visit and play, through which the memory of their own play is preserved.

\section{B. Feasibility of applying Qiang embroidery pattern to cultural and creative products}

It is necessary to take the Qiang embroidery pattern as the source of design, grasp the national characteristic 
culture contained in the embroidery pattern, use the carrier of cultural and creative products to better show the art behind the embroidery pattern, and integrate the Qiang national characteristic culture into the cultural and creative products. [6] Cultural and creative products have the function of transmitting cultural connotation and are endowed with cultural significance. Qiang embroidery pattern is the symbol of Qiang nationality and the symbol of national wisdom. By using the diversity of Qiang embroidery pattern, the pattern art is transformed and its implicit cultural connotation is taken to achieve better results. Cultural and creative products ensure the uniqueness and the dominant culture of embroidery patterns. Through the carrier of cultural and creative products, people can spread the unique culture of Qiang nationality and carry forward the traditional culture. Finally, it has a positive role in promoting the sustainable development and innovation of national culture, and also has a certain guarantee for the innovative cultural and creative products of Qiang embroidery pattern based on the market.

According to John Robert, director of cultural and creative development of British Museum, "the principle we follow is to avoid making derivatives have cheap consumption quality or loss cultural nature due to new fashion design". [7] This paper points out that in the process of cultural and creative design, it is required to keep the national culture and spiritual civilization, grasp the cultural elements on a scale and preserve the national uniqueness. In the process of product and pattern combination, attention should be paid to the relationship between pattern reorganization and product structure adaptation, that is, the combination of shape and modeling. In the process of development, Qiang embroidery patterns are combined with the characteristics of other ethnic patterns, conforming to the rules of formal beauty, and forming several forms of Tuanhua, Jiaohua and Bianhuadeng. The composition of Qiang embroidery patterns is flexible and changeable, which embodies the unique aesthetic and design ideas of Qiang people and provides better creative inspiration for the design of cultural and creative products.

\section{Feasibility of applying Qiang embroidery colors to cultural and creative products}

Color is one of the important attributes of patterns Without color, patterns have no expressiveness. Different color combinations of the same patterns convey different emotions. Qiang embroidery often uses contrast and complementary colors, with black, blue and white as the base color and red, yellow, blue and green as the embroidery thread color. The color contrast is strong, bright and gorgeous, showing unique national characteristics and highlighting simple national personality. [8] Using this color matching principle in the color matching of cultural and creative products can correctly reflect the national personality of Qiang nationality and resonate deeply in emotion. Plekhanov once said: "the art of any nation is determined by its psychology, which is caused by its situation." Color plays an important role in conveying product emotion. The application of Qiang embroidery pattern color in cultural and creative products not only reflects the unique opinions of Qiang people on color, but also makes cultural and creative products unique, adding aesthetic feeling. Qiang embroidery pattern color provides color basis for cultural and creative product design, and highlights the unique aesthetic and national charm of the Qiang people. The combination of Qiang embroidery pattern color and cultural and creative products can better express the designer's design intention, which plays a positive role in promoting national characteristics.

\section{Feasibility of applying Qiang embroidery pattern technology to cultural and creative products}

1) Being customized: Ancient Qiang embroidery is a kind of handicraft with various needling techniques. Different needling techniques express different emotions, with functions and aesthetics. Different from mechanized production products, each one has its own characteristics. Through each work, people can see the different feelings of the producer for life. [9] Exquisite techniques and patterns are applied to cultural and creative products. Traditional crafts are combined with cultural and creative products, and innovation is carried out on the premise of retaining some crafts. The aesthetics is improved. Each product is "customized".

2) Inheritance and development: Cultural and creative products give cultural creativity to products. Different from general products, they have economic value and cultural connotation at the same time. They have certain influence on the spread of culture. Qiang embroidery has rich patterns and techniques, which is conducive to the development of cultural and creative products. Cultural and creative products focus on the new design of Qiang embroidery patterns and techniques, absorb new elements, innovate and utilize the techniques in multiple dimensions, and create new works. At present, most of the cultural and creative products use the essence of national culture for reference, and extract the unique elements of the nation for application. The combination of tradition and modern is feasible, which is the combination of inheritance and development. Through the new techniques, people can inject fresh blood into the traditional techniques, find new clothes for the traditional techniques, which are integrated with each other. The inheritance needs to be promoted by the 
development, and the development needs the support of the inheritance. With the perfect combination of the two, it must be developed in the right direction, that is to say, the development of Qiang embroidery pattern techniques needs to be promoted by the innovation, while the innovation of cultural and creative products needs to be consolidated by the inheritance.

\section{CONCLUSION}

The natural disaster in Wenchuan in 2008 caused a certain degree of damage to the natural environment and national culture of the Qiang people. In the postdisaster reconstruction, national culture is one of the rescue projects. Some enterprises and artists start with the Qiang culture, take the Qiang embroidery pattern as the source, combine the traditional pattern art with modern industrial products, and spread the Qiang culture.

Pattern art and products form a symbiotic and mutually beneficial relationship. It is feasible to combine Qiang embroidery pattern art with cultural and creative products. However, it cannot simply copy the pattern. In the design process, the pattern is refined to show the national culture under the pattern. It plays an inspiring role in the spread of a national characteristic culture, endows cultural and creative products with profound historical and cultural connotation, and improves the style and taste of products.

The pattern art of Qiang embroidery is extracted by the Qiang people through their own wisdom after hundreds of years. It is the national identification symbol and symbol. Cultural and creative products are the carrier of cultural communication. The combination of the two is the embodiment of inheritance and innovation. It is also the inheritance and development of traditional pattern art through modern technology and techniques. Through the feasibility study on the application of Qiang embroidery pattern art to cultural and creative products, it is conducive to the sustainable development of Qiang embroidery and the protection of the endangered intangible cultural heritage culture. Cultural and creative products are the tools to promote the development of traditional culture and play a positive role in the promotion of national culture. Combining the spiritual culture of cultural and creative products with new technology is conducive to the spread and promotion of national culture.

\section{References}

[1] Zhang Taiming. The historical trace of embroidery of Qiang nationality [J]. Guizhou Ethnic Studies, 1995. (in Chinese)

[2] Shen Lei, Xu Jing. Pattern Themes and Cultural Connotation of Qiang Minority Embroider [J]. Hundred Schools in Art, 2011. (in Chinese)
[3] Lu Qianqian. Research and Design Innovation of Qiang Embroidery in Luobozhai, Wenchuan from the Perspective of Artistic Anthropology [D]. Sichuan Normal University, 2018. (in Chinese)

[4] $\mathrm{Hu}$ Boyang. Aesthetic interpretation of Qiang embroidery patterns [J]. Caizhi. 2013, 14: 273. (in Chinese)

[5] Zhou Jianfeng, Huang Lifan. The use of traditional elements in the design of cultural and creative products $[\mathrm{J}]$. Art Observation, 2018. (in Chinese)

[6] Qian Jue, Zang Yong. Artistic Beauty of Qiang Embroidery [J]. Hundred Schools in Art. 2012, Issue 7: 58-60. (in Chinese)

[7] Chen Zhongyan, Qiang embroidery pattern from the perspective of non-genetic inheritance and its application in cultural and creative products [D]. Guangxi Normal University, 2018. (in Chinese)

[8] Zhong Wei. Local Handicraft Resources Recognition and Cultural Creativity Design Transformation of Qiang Embroidery [J]. Packaging Engineering, 2017. (in Chinese)

[9] Zhou Jianfeng, Huang Lifan. The use of traditional elements in the design of cultural and creative products $[\mathrm{J}]$. Art Observation, 2018. (in Chinese) 